\title{
Achterbahnfahrt mit dem Bundesrat
}

\section{Yvonne Gilli}

Dr. med., Präsidentin der FMH

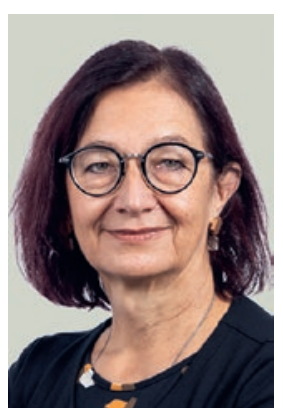

Die Wellen dieser Pandemie erinnern an eine Achterbahnfahrt - mit mehreren Besonderheiten: In der Pandemie-Achterbahn geht es schneller aufwärts als abwärts und sie ist gefährlich. Regelmässig werden Menschen hinausgeschleudert, werden verletzt und sterben sogar, bei höheren Anstiegen besonders viele. Es gibt zu wenig Sicherheitsgurte, sie wurden zwar bestellt, doch bis alle einen erhalten, könnte es noch eine ganze Weile dauern. Nach über einem Jahr der Fahrt wissen wir immer noch nicht, welches die gefährlichen Kurven sind und welche Vorkehrungen die Menschen wie gut schützen. Darum sollen sich alle gut festhalten, denn die Bahn bremst mal mehr, mal weniger stark und zuckelt im Schneckentempo dahin. Der Unmut unter den Fahrgästen wächst.

Im April 2021 reagiert der Bahnbetreiber auf die immer lautere Kritik der Ausgebremsten, die in der Bahn feststeckend verzweifeln. Man könne nun trotz steigender Fallzahlen wieder Gas geben und die behördlichen Massnahmen zur Bekämpfung der Pandemie stark lockern. Vier der fünf Stoppschilder, die der Bahnbetreiber selbst zuvor aufgestellt hat, überfährt

\section{Was wie ein Lob der Bevölkerung klingt, wälzt tatsächlich die Verantwortung für die Zahl der Neuinfektionen auf diese ab.}

er dabei. Ob er Angst gehabt hätte, dass die Leute die Geduld verlieren? Nein, die meisten verhielten sich verantwortungsvoll, es könne funktionieren, wenn alle «sehr gut mitmachen».

Was wie ein Lob der Bevölkerung klingt, wälzt tatsächlich die Verantwortung für die Zahl der Neuinfektionen auf diese ab und ignoriert die Verpflichtungen des Bahnbetreibers. Zugegeben, es kommt oft nicht darauf an, was die Politik beschliesst, sondern darauf, was sie selbst und die Leute tun. In der Medizin nennen wir das Einhalten eines Therapieplans Compliance oder Adhärenz. Die Therapie ist immer nur so gut wie das, was beim Patienten ankommt. Genauso ist Pandemiepolitik nur so gut wie das, was in der Bevölkerung ankommt. Dies mindert jedoch nicht die Bedeutung des Therapieplans, im Gegenteil, es erhöht den Anspruch an seine Qualität. Die Kunst in Medizin und Politik ist es, theoretisch gute Pläne mit einer erfolgreichen praktischen Umsetzung zu verbinden.

Was also tun, wenn es bei der Umsetzung harzt, die Compliance nachlässt? Man kann auf Autorität setzen, wie in Ostpreussen 1710, als auf Verstösse gegen die Pest-Massnahmen der Tod durch Erhängen drohte [1]. Man kann aber auch selbstkritisch über die Bücher gehen und sich fragen, wo die Therapie bislang nicht überzeugt hat: Wurden die richtigen Massnahmen erfolgreich aufgegleist? Welche Wirkungen, welche Nebenwirkungen zei-

Unzufriedenheit kann zeigen, dass der Therapieplan nicht ausreichend praxistauglich ist.

gen sie? Welche Kosten, welchen Nutzen? Und haben wir aus dem bisherigen Behandlungsverlauf gelernt und alle neuen Möglichkeiten genutzt? Zeigt die Unzufriedenheit, dass die Bringschuld für die bestmögliche und am wenigsten belastende Therapie nicht erfüllt wurde, der eigene Plan nicht ausreichend praxistauglich ist?

Unser Bahnbetreiber wählt einen dritten Weg. Er bewirtschaftet Probleme, indem er je nach Lautstärke des Protests mal mehr, mal weniger bremst und, selbst gut angeschnallt, die Menschen auffordert, sich besser festzuhalten. Er handelt ähnlich wie ein Arzt, der das immer gleiche Medikament mal niedriger, mal höher dosiert - und den Patienten zur korrekten Einnahme ermahnt. Mit reduzierter Dosis lassen die Nebenwirkungen nach - aber auch die Wirkung und umgekehrt. Nach einem Jahr der Pandemie sollten wir wissen, welche Kurve wie gefährlich ist, und gezielter handeln können. Wir sollten eine Teststrategie haben, die diesen Namen verdient. Wir sollten die teure Achterbahnfahrt mit Hilfe kostendeckender Impfungen in Arztpraxen verkürzen. Wir sollten über Impfzertifikate verfügen und über ein Konzept, was wir tun, falls es bald schon wieder neue Gurte braucht. All dies läge in der Verantwortung des Bahnbetreibers. Ein Stop-andgo in der Hoffnung, dass sich alle gut genug festhalten, bis es ausreichend Sicherheitsgurte hat, reicht nicht.

\footnotetext{
Literatur

1 Fox W. Compliance of patients and physiscians: experience and lessons from tubercolosis. Br Med J. 1983;287(6384):33-5.
} 